RECEBIDO EM 02/06/2012. ACEITO EM 27/08/2012.

\title{
Implementação do gerenciamento por categorias para medicamentos em uma rede farmacêutica
}

Carla Simone Ruppenthal Neumann

Escola de Administração - UFRGS

csrneumann@ea.ufrgs.br

\section{Bárbara Severo dos Santos}

Departamento de Produção e Transportes - UFRGS

basevero@hotmail.com

\section{Carla Schwengber ten Caten}

Programa de Pós-Graduação em Engenharia de Produção - UFRGS

tencaten@producao.ufrgs.br

\section{RESUMO}

Devido ao crescimento do mercado de varejo farmacêutico, às mudanças recentes na forma de exposição dos produtos e à necessidade de entender os consumidores, realizou-se a implementação do gerenciamento por categorias para medicamentos em uma rede farmacêutica. O gerenciamento por categorias possibilita a análise dos produtos trabalhados em grupos de itens que possuam características semelhantes entre si, além de melhorar o atendimento às necessidades do consumidor. Por meio da análise de dados, conhecimento dos produtos e reuniões com os gestores da empresa foi possível entender as particularidades do mercado e definir estratégias, metas e ações para cada categoria. $\mathrm{O}$ diferencial desse trabalho é propor indicadores que comparam os diferentes medicamentos para compor um indicador global. Os resultados obtidos permitem classificar as diferentes categorias a partir de um indicador global, possibilitando a seleção de categorias e produtos para o desenvolvimento de ações diferenciadas.

Palavras-chave: gerenciamento por categorias; medicamentos; rede de varejo.

\begin{abstract}
Due to the growth of the pharmaceutical retail market, recent changes in the form of exhibition of products and the need to understand consumers, structured the implementation of Category Management for pharmaceutical drugs in a network. The category management enables the analysis of the products worked in groups of items that have similar characteristics to each other, besides having the purpose to meet consumer needs. Through data analysis, knowledge of products and meetings with company managers could understand the particularities of the market and define strategies, goals and actions for each category worked. The differential of this work is to propose indicators that compare the different drugs to compose an overall indicator. The obtained results allow to classify the different categories from a global indicator, allowing the selection of categories and products for the development of actions for each different category.
\end{abstract}


Keywords: category management; medicine; retail network.

\section{Introdução}

O mercado farmacêutico mundial está crescendo. Segundo o IMS Health (2011), nos últimos cinco anos os gastos com medicamentos cresceram em média 6,2\% ao ano. Para 2015, a previsão mundial é de um crescimento de $3 \%$ a $6 \%$ anuais, alcançando quase 1,1 trilhões de dólares, gerada pela quebra de patentes de medicamentos, crescimento do mix de produtos oferecidos e o aumento do mercado consumidor. A atividade de venda a varejo de artigos farmacêuticos, médicos, ortopédicos e de perfumaria, registrou crescimento de $9,7 \%$, em relação ao ano de 2010. A estabilidade do emprego, expansão da massa de salários e disponibilidade do crédito, somado ao caráter de uso essencial e permanente de seus produtos, são os principais fatores explicativos do desempenho positivo pelo oitavo ano consecutivo do segmento (IBGE, 2011).

Em paralelo a este cenário, os estabelecimentos farmacêuticos têm realizado uma série de adequações necessárias em relação à legislação. Como exemplo, cita-se a Resolução da Diretoria Colegiada 44/2009 (ANVISA, 2009a), que determina que os medicamentos estejam alocados ao alcance dos funcionários e não dos clientes. Sem a possibilidade de utilizar o autosserviço, diminuem as chances das vendas por impulso, sendo necessário adotar uma estratégia frente à possível redução nas vendas.

Observa-se que o posicionamento dos produtos expostos influencia diretamente na decisão de compra. Em um estudo que analisou a venda de analgésicos e antitérmicos em redes de farmácias do Rio de Janeiro, Melo e Lima (2009) identificaram que os medicamentos com maior representatividade em vendas dentro das categorias analisadas são aqueles que estão mais visíveis aos clientes. Costa et al. (2003), na aplicação de uma ferramenta multicriterial para selecionar o mix de produtos de uma determinada categoria, salientam a importância da determinação de variáveis significativas para avaliação, bem como a utilização de pesos adequados. Como exemplos de variáveis relacionadas à venda de produtos podem-se citar o preço, a margem e a média de venda.

Para Blessa (2003) a visão é um sentido humano que tem muita influência no momento da escolha, pois faz com que o consumidor deseje o produto. Por este motivo, os produtos mais evidentes no ponto de venda têm vantagem em relação aos concorrentes em determinada categoria. Além disso, o posicionamento correto pode induzir o cliente a adquirir um produto que não tinha necessidade ou que não tinha a intenção de comprar. A exposição bem feita traz vantagens, pois facilita a compra, evidencia as necessidades e economiza tempo, aumenta a lucratividade, valoriza o espaço físico, cria a fidelidade à marca, bloqueia as ações da concorrência e aumenta a rotatividade dos produtos.

Partindo da necessidade de chamar a atenção do consumidor sem que ele tenha acesso direto aos medicamentos, é preciso estudar o mix de produtos trabalhados por meio da percepção do consumidor. Esta visão pode ser alcançada através do gerenciamento por categorias, que é uma das ferramentas do Efficient Consumer Response, ou Resposta Eficiente ao Consumidor (ECR). Esta ferramenta sugere o agrupamento de produtos que atendam as mesmas necessidades, permitindo a análise comparativa dentro de cada categoria em relação às vantagens que a venda de cada produto trará à empresa e ao consumidor (ECR BRASIL, 2001).

O objetivo desta pesquisa é apresentar a implementação do gerenciamento por categorias para medicamentos ilustrada em um caso prático em uma rede de farmácias do sul do Brasil. Esta ferramenta possibilita a priorização dos medicamentos que serão expostos por meio de critérios como preço, margem de lucro e volume de vendas. Além de elencar os medicamentos que devem ter maior atenção no ponto-de-venda, uma avaliação de 
desempenho das categorias permite a definição de estratégias diferenciadas para cada uma, de acordo com os objetivos da empresa. Realiza-se um esforço para encontrar indicadores quantitativos que permitam a comparação entre diferentes categorias de medicamentos.

\section{Determinações Legais que Influenciam a Venda de Medicamentos}

No Brasil, duas determinações influenciam diretamente no resultado de vendas de medicamentos atualmente, que são a RDC 44/2009 e a RDC 44/2010.

A Resolução da Diretoria Colegiada 44/2009 (ANVISA, 2009a) determina que a possibilidade de exposição dos medicamentos depende da categoria em que está classificado de acordo com o registro junto à Agência Nacional de Vigilância Sanitária (ANVISA). Os medicamentos devem permanecer fora do alcance dos consumidores com exceção de alguns tipos de medicamentos que podem permanecer no autosserviço. De acordo com a Instrução Normativa $n^{0} 10 / 2009$ (ANVISA, 2009b), os medicamentos que podem ser expostos no autosserviço são aqueles classificados em três categorias: (i) fitoterápicos, que são os medicamentos elaborados com matérias-primas vegetais; (ii) dermatológicos, que são os medicamentos aplicados topicamente, ou seja, que agem no local em que são aplicados; e (iii) medicamentos sujeitos a notificação simplificada, que são, por exemplo, água oxigenada, glicerina e soro fisiológico.

Já a Resolução da Diretoria Colegiada 44/2010 (ANVISA, 2010), com o objetivo de combater o uso indiscriminado de antibióticos, determina que a venda destes medicamentos apenas deve ser realizada com a retenção de receita. Para a empresa foco deste estudo de caso, após a determinação, a venda de antibióticos sofreu uma queda de aproximadamente $25 \% \mathrm{em}$ relação ao mesmo período do ano anterior.

\subsection{Resposta Eficiente ao Consumidor (ECR)}

A Resposta Eficiente ao Consumidor (ECR) surgiu para estabelecer práticas que possibilitassem o relacionamento baseado em confiança para a gestão colaborativa entre empresas pertencentes a uma cadeia de suprimentos (BARRATT e OLIVEIRA, 2001). Ramuski (2004) observa que, mesmo havendo diferenças sobre o comportamento do consumidor, a maioria dos autores cita três aspectos em comum: (i) a parceira entre empresas; (ii) a busca da eficiência operacional para a redução de custos; e (iii) o aumento do valor oferecido ao consumidor.

Segundo Pires (2004), para alcançar a redução dos custos gerados pelos processos pertencentes às empresas envolvidas, a implementação da ECR é baseada em quatro grandes estratégias: reposição, sortimento, promoção e introdução eficiente de produto. A reposição eficiente de produto otimiza os processos envolvidos com a reposição dos produtos, processos tais como a informatização do envio de pedidos, a separação e o recebimento da carga, a redução do nível de estoque, a previsão correta de demanda, etc. O sortimento eficiente de produto oferece ao consumidor a correta e eficiente oferta de produtos no ponto de venda, proporcionando o aumento das vendas e do giro de estoque. A promoção eficiente de produto utiliza o sistema de promoção dos produtos de forma correta, com o objetivo de alcançar o consumidor e beneficiar o revendedor. A introdução eficiente de produto estuda o desenvolvimento e lançamento de novos produtos, além de dimensionar a demanda, analisar concorrentes e preços e entender a necessidade do consumidor.

Estas estratégias são apoiadas por uma série de práticas e ferramentas sugeridas como reposição contínua, gerenciamento por categorias, sistema de recepção eletrônica, cross docking, EDI (Eletronic Data Interchange), custeio baseado em atividades, etc. (COSTA; BRAZIL; OLIVEIRA, 2003). 
Das quatro estratégias descritas, esse artigo aborda principalmente o sortimento e a promoção eficiente do produto. Devido à resistência à mudança, falta de liderança (comprometimento da direção), a falta de confiança entre as empresas, os aspectos tecnológicos (alto investimento em tecnologia e atualizações) e a falta de foco no consumidor encontram-se dificuldades ao implementar novos projetos e realizar alterações na rotina das empresas (ECR BRASIL, 1998a).

\section{Gerenciamento por Categorias}

Para aplicar o gerenciamento por categorias é necessário entender a visão e as necessidades do consumidor. Uma categoria é definida pelo agrupamento de produtos que podem ser substituíveis entre si e que atendem às mesmas necessidades. Por sua vez, o gerenciamento por categorias é um processo em que varejistas e fornecedores tratam as categorias como diferentes unidades estratégicas de negócio, definindo metas e medindo resultados para cada uma (ECR BRASIL, 1998b). Por outro lado, Ramuski (2004) apresenta a ideia de que uma categoria pode abranger produtos de aplicação semelhante e não apenas produtos com a mesma finalidade, oferecendo soluções completas para o cliente. Por exemplo, no caso de algodão, a categoria a que este produto pertence poderia incluir também gaze, esparadrapo e curativos, formando a categoria pronto socorro.

Grande parte dos artigos sobre gerenciamento por categorias encontrados na literatura retratam estudos de caso em supermercados. Porém, os conceitos também podem ser utilizados para outros tipos de varejo, a exemplo do estudo realizado por Hauck (2008), que apresenta resultados de crescimento de mais de $18 \%$ do faturamento da categoria estudada em uma rede de farmácias.

Segundo a ECR Brasil (1998b), o gerenciamento por categorias demanda investimento em tempo, tecnologia e recursos. Porém, quando bem estruturado apresenta resultados positivos para a empresa em relação ao mercado competitivo. Para tanto está baseado em seis componentes básicos: (i) estratégia, (ii) processo de negócios, (iii) cartão de metas, (iv) capacidade da organização, (v) informática e, (vi) relacionamentos de colaboração com parceiros comerciais (MARQUES; ALCÂNTARA, 2004). As estratégias da empresa devem ser definidas e claras para cada categoria como uma unidade de negócio. Este componente depende do comprometimento da direção da empresa e da definição de estratégias geral, de marketing, do financeiro, de abastecimento, de relacionamento com o fornecedor, etc. $\mathrm{O}$ processo de negócios é a definição do planejamento de atividades desenvolvidas para cada categoria, com a finalidade de determinar um plano de negócios para o varejista e o fornecedor. O cartão de metas é o conjunto de ferramentas utilizado para definir, medir e avaliar as categorias de acordo com os objetivos determinados na estratégia de cada uma. A capacidade da organização é fundamental para obter resultados positivos com o gerenciamento de categorias. Para tanto, é necessário o envolvimento da alta gerência, o investimento em treinamento de pessoal, a disponibilidade dos dados necessários às análises, a definição das responsabilidades de cada setor e a clareza dos conceitos e ferramentas utilizadas. A informática é o componente que indica a necessidade de investir fortemente em tecnologia, com o objetivo de possibilitar apoio à análise de dados (preços, marcas, dados de venda e rentabilidade), apoio à tomada de decisão, avaliação de desempenho, etc. $\mathrm{O}$ bom relacionamento de colaboração com parceiros comerciais é fundamental para o funcionamento dos princípios do ECR. Os dois lados da negociação, varejistas e fornecedores, devem obter vantagens para construir parcerias nestas relações.

Para o componente processo de negócios, Merlo et al. (2004) apresentam uma metodologia com três macro etapas, subdivididas em oito etapas, conforme a Figura 1. A macro etapa 1 envolve duas etapas: (i) definição das categorias, que é a divisão dos produtos trabalhados pela empresa a partir das necessidades dos clientes; e (ii) definição do papel de 
cada categoria. A análise de dados engloba apenas uma etapa, avaliação das categorias, e requer tecnologia para a análise de um grande volume de dados. Os dados analisados influenciam diretamente na percepção de oportunidades e na definição das estratégias.

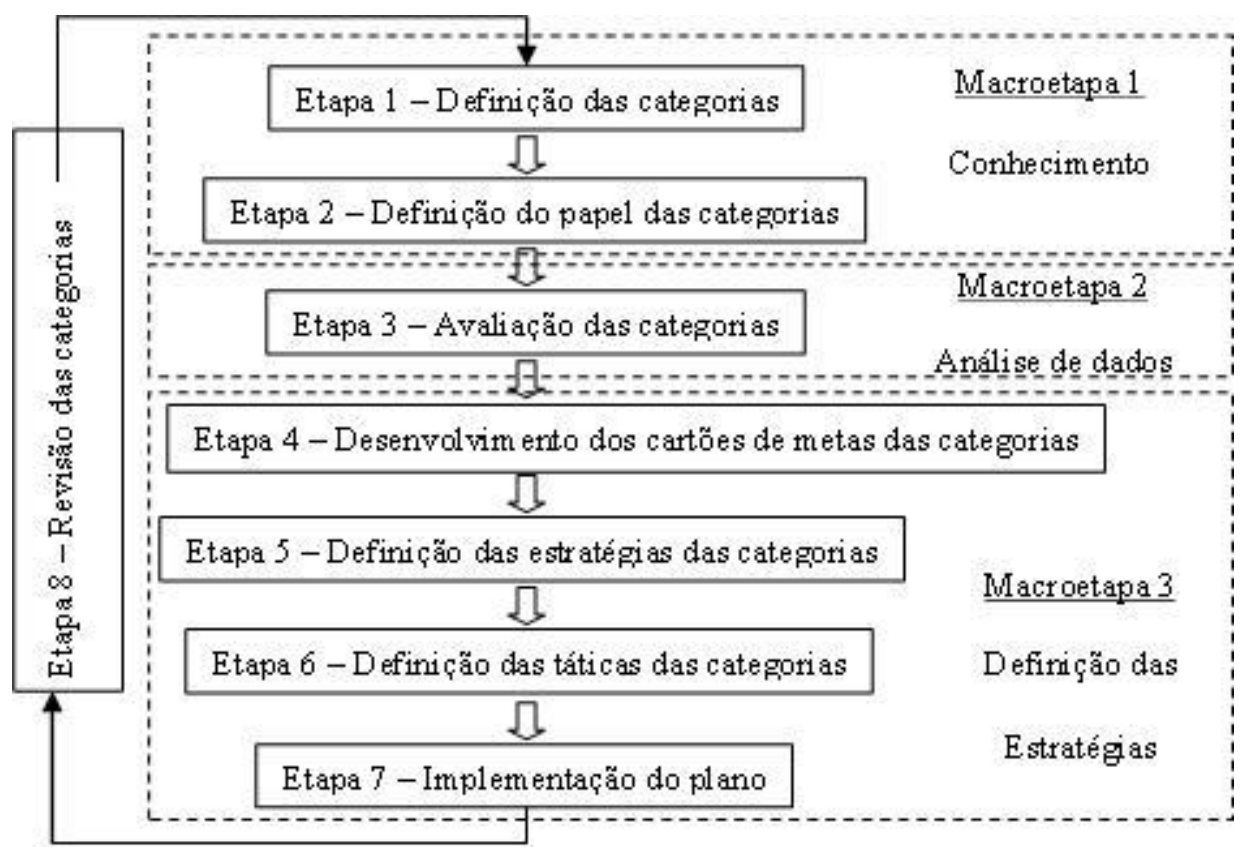

Figura 1 - Procedimento metodológico do gerenciamento por categorias Fonte: Merlo et al. (2004)

A macro etapa 3 é formada por quatro etapas: (i) desenvolvimento do cartão de metas, que consiste na definição e documentação do acompanhamento de desempenho das categorias; (ii) definição das estratégias das categorias, realizada a partir da informação das metas de venda e faturamento de cada uma; (iii) definição das táticas das categorias, que são as ações necessárias para realizar as estratégias definidas; e (iv) implementação do plano. Como o mix de produtos deve estar sempre em avaliação, ao final das três macroetapas faz-se a revisão das categorias. Para simplificação da aplicação, Merlo et al. (2004) utilizam apenas as macro etapas no estudo apresentado, sendo que neste trabalho serão utilizadas as 8 etapas desmembradas, que serão apresentadas na seção 3.

\section{Métodos para a Análise}

A análise realizada para a avaliação das categorias neste artigo é baseada na revisão de dois conceitos, a classificação $\mathrm{ABC}$ e a avaliação de desempenho. Para a divisão em grupos de produtos com comportamento de venda parecidos, a classificação ABC determina, para a maioria dos casos, que uma menor parte de produtos representa a maior parte das movimentações financeiras totais. Desta maneira, os produtos se classificam da seguinte forma: (i) itens classe A são os principais geradores de valor, pois representam $80 \%$ da movimentação em valor e $20 \%$ em número de produtos; (ii) itens classe B são produtos de média importância para a empresa, pois representam $10 \%$ do valor total e $30 \%$ do número de itens; e (iii) itens classe C são itens baratos e de baixo giro, pois representam $10 \%$ do valor movimentado e $50 \%$ do número de itens. Ao discorrer sobre a importância dos diferentes produtos pertencentes ao portfólio das empresas, Pinheiro (2005) comenta que alguns poucos produtos podem ter maior importância por representarem mais valor em vendas, mesmo que a sua representatividade em unidades vendidas não seja alta. Da mesma forma, alguns produtos 
que apresentam grande número de volumes movimentados podem não trazer alto retorno para a empresa.

O posicionamento dentro de cada categoria é construído através da avaliação de desempenho de cada um. Segundo Slack et al. (2007), as medidas de desempenho têm o objetivo de quantificar o trabalho das organizações, refletindo as necessidades dos consumidores finais. Muller (2002) salienta que os indicadores de desempenho devem medir se a empresa está agindo de acordo com os seus objetivos iniciais, ou seja, se as atividades desenvolvidas refletem as definições estratégicas da empresa. Os resultados observados através das medidas de desempenho servem de apoio gerencial à tomada de decisão. Além disso, possibilitam o entendimento da situação atual da empresa e o entendimento do que pode acontecer (FERREIRA, 2009). Por exemplo, o conhecimento sobre a variação de vendas das diferentes categorias de medicamentos ao longo dos últimos anos permite prever e preparar o ponto de venda para as categorias que terão crescimento na próxima estação.

A partir de revisão na literatura sobre casos que envolvem a avaliação de desempenho de vendas, pode-se perceber a utilização de alguns indicadores em comum. $O$ estudo de Bortoluzzi et al. (2010) analisou as práticas de avaliação de desempenho de empresas e identificou os seguintes indicadores: retorno sobre o investimento, variação das vendas, variação da margem de lucro, margem de lucro, nível de vendas, nível de fluxo de caixa, fatia de mercado, entre outros. Os estudos de Camargos e Barbosa (2005), Albuquerque e Escrivão (2007), Chiusoli e Pacagnan (2009) e Klotzle (2003) consideram rentabilidade, participação de mercado, volume de vendas, vendas líquidas, margem, evolução de vendas os principais indicadores para esta avaliação.

\section{Procedimentos Metodológicos}

A empresa em que o estudo é desenvolvido atua no mercado farmacêutico desde o ano de 1973, quando começou a atuar com 33 lojas a partir da junção de duas redes de farmácias. Atualmente conta com 282 filiais, distribuídas na região Sul do Brasil. São gerenciados aproximadamente 15.000 itens, sendo 6.000 medicamentos e 9.000 produtos de perfumaria. A rede conta com um laboratório farmacêutico, uma distribuidora e um conjunto de filiais (farmácias), cujo diferencial competitivo é justamente esse envolvimento com o setor de compras da distribuidora. Esta integração aproxima os fornecedores e o varejo, ocasionando a necessidade de estimular ainda mais a parceria entre eles.

Devido às restrições da RDC 44 foi necessário desenvolver novos espaços para a exposição de medicamentos. Desde então, as filiais trabalham com três tipos de exposição: (i) a exposição no autosserviço, para aqueles medicamentos que ainda podem permanecer ao alcance do consumidor; (ii) a exposição nas prateleiras existentes atrás do balcão, que são utilizadas para a exposição de medicamentos genéricos e de MIPs, em que os clientes podem visualizar os medicamentos, mas apenas os funcionários têm acesso direto e; (iii) a exposição no balcão vitrine, que é um balcão de vidro onde são expostos os medicamentos avulsos permanecendo à vista ao consumidor, mas ao alcance apenas dos funcionários. Este estudo pode ser utilizado para a priorização de medicamentos para os três tipos exposição utilizados pela empresa.

A empresa conta com um banco de dados, que facilita as análises necessárias para o gerenciamento por categorias. Possui um cadastro de medicamentos para validar informações como classe do medicamento (referência, genérico, similar, fitoterápico, etc.), registro no ministério da saúde, apresentação (comprimido, drágea, xarope, solução, etc.), marca, classe terapêutica, entre outras.

O estudo é de natureza aplicada, pois possibilita a utilização do método para solução de um problema específico. A abordagem utilizada é quantitativa, pois os resultados são analisados por meio de indicadores obtidos do banco de dados da empresa estudada (dados 
quantificáveis). Como busca apresentar e entender os resultados obtidos por meio de análises de dados quantitativos, a pesquisa tem objetivo de caráter descritivo. Por fim, utiliza elementos de pesquisa-ação, pois o artigo tem como objetivo a resolução de um problema específico, sendo essencial a participação dos envolvidos na empresa para a execução (MORESI, 2003). Utiliza-se o procedimento metodológico proposto por Merlo et al. (2004), citado na seção 2.2, visualizado na Figura 1, na forma de oito etapas, com pequenas adaptações para possibilitar a aplicação no segmento de medicamentos e para enfocar com mais detalhes a diferenciação entre as categorias. Uma contribuição importante dessa pesquisa é o detalhamento de aspectos práticos do gerenciamento por categorias, como a exemplificação de papéis e a definição de indicadores para formação das categorias. A partir desse ponto, esta seção apresenta detalhadamente cada uma das etapas necessárias para implementar o gerenciamento por categorias.

$\mathrm{Na}$ etapa 1 são criadas as diferentes categorias e os produtos comercializados são distribuídos entre as categorias, a partir de características comuns que possuam. Esta classificação tem como objetivo analisar produtos parecidos, sem a necessidade de analisá-los um a um. A criação das categorias e a distribuição dos produtos entre elas são realizadas a partir de reuniões de equipes multifuncionais com conhecimento sobre os produtos em questão. Para a distribuição dos produtos entre as categorias, sugerem-se questionamentos sobre os produtos, como, por exemplo, finalidade para qual é utilizado, quem o utiliza, como se utiliza, quais os benefícios advindos do seu uso, etc. Como exemplos de categorias de medicamentos podem-se citar circulatórios, gastrointestinais, oncológicos e vitaminas. Devido ao alto número de itens comercializados por empresas de varejo, as categorias são definidas a partir de características gerais dos itens e características específicas são definidas por meio de subcategorias.

A etapa 2 define o papel da categoria, reproduzindo as necessidades do consumidoralvo. Esta etapa é essencial, pois sua definição pode influenciar diretamente e diferenciar as ações a serem tomadas. Na literatura, usualmente são citados quatro possíveis papéis: (i) papel de destino, (ii) papel de rotina ou preferido, (iii) papel ocasional ou sazonal, e (iv) papel de conveniência, cujas características são detalhadas na Tabela 1.

Tabela 1 - Principais características dos papéis de categorias Fonte: Adaptado de ECR (1998b)

\begin{tabular}{cl}
\hline Papel da Categoria & \multicolumn{1}{c}{ Características } \\
\hline \multirow{2}{*}{ Destino } & Reforçam a imagem do varejista como principal provedor dos produtos desta categoria \\
& $\begin{array}{l}\text { Devem ser o principal foco de ações para todos os setores da empresa } \\
\text { Representam de 5 a 7\% das categorias }\end{array}$ \\
\hline \multirow{2}{*}{ Rotina (preferido) } & Reforçam a imagem do varejista provedor preferido destes produtos \\
& $\begin{array}{l}\text { Devem oferecer valor comp etitivo para o consumidor } \\
\text { Representam de 55 a 60\% das categorias }\end{array}$ \\
\hline \multirow{2}{*}{ Ocasional (sazonal) } & Peforçam a imagem do varejista um provedor importante destes produtos \\
& Representam de 15 a 20\% das categorias \\
\hline \multirow{2}{*}{ Conveniência } & Tornam o varejista uma opção de parada única para compras \\
& Possuem papel importante na geração de capital para a empresa \\
& Representam de 15 a 20\% das categorias \\
\hline
\end{tabular}

A etapa 3 permite verificar se o desempenho dos produtos está alinhado com os objetivos da empresa. Esta etapa é caracterizada pela análise de um grande volume de dados. Por este motivo, espera-se que a empresa que deseja implementar o gerenciamento por categorias possua um sistema de tecnologia da informação suficientemente desenvolvido para possibilitar o acesso a ferramentas de gestão de informações. Para possibilitar a avaliação por meio de comparação entre as categorias, utilizam-se indicadores de avaliação de desempenho. A seleção dos indicadores deve ser realizada em conjunto entre a equipe de gerenciamento por 
categorias e os gestores responsáveis. Os indicadores selecionados para a avaliação devem medir aspectos que a empresa tenha interesse em manter ou melhorar o desempenho, ou seja, os aspectos mais representativos para o negócio. Em relação à medição de desempenho de produtos, os indicadores mais encontrados na literatura são representados pelas equações (1), (2), (3) 3 (4).

Fatia de mercado=Venda em quantidadeQuantidade vendida da categoria

Rentabilidade $(\%)=$ Venda em valorValor de compra $\times 100$

Valor vendido $=$ Valor de venda $\times$ Venda em quantidade

Giro de estoque $=$ custo da mercadoria vendidamédia de estoque do período

No caso de todos os indicadores de desempenho serem do tipo maior é melhor, devese buscar a maximização dos resultados (GUEDES, 1996). Desta maneira, o indicador global de desempenho de cada produto pode ser calculado por meio da média dos resultados obtidos para cada indicador. A utilização de um indicador global permite a classificação dos produtos dentro de cada categoria, indicando os itens que devem receber maior foco para o varejista. $\mathrm{O}$ indicador global de desempenho da categoria é calculado por meio da soma do desempenho de cada medicamento que a ela pertence. Após o cálculo do indicador global das categorias, é possível realizar a classificação $\mathrm{ABC}$, indicando as categorias mais representativas para a empresa.

Para verificar se os produtos estão apresentando um bom desempenho em relação aos indicadores selecionados é necessária a definição de metas. A etapa 4 possibilita a documentação e acompanhamento dos parâmetros de desempenho de cada categoria. Os parâmetros utilizados são os indicadores que fazem parte da avaliação de desempenho da categoria. As metas são definidas a partir do histórico de vendas de cada categoria e da previsão de crescimento, além da análise de possíveis eventos externos do mercado. Também é levado em consideração o papel da categoria, que determina o tratamento diferenciado que cada categoria deve receber. Os resultados devem ser documentados pela equipe de gerenciamento por categorias e apresentado aos gestores da empresa.

O principal objetivo do gerenciamento por categorias é gerenciar os diferentes grupos de produtos como se fossem unidades estratégicas de negócio diferentes. A correta execução da etapa 5 é fundamental para alcançar este objetivo. Nessa etapa são definidos os princípios a serem seguidos para alcançar as metas decididas anteriormente e para realizar o papel de cada categoria. As estratégias devem estar alinhadas aos objetivos da empresa, por isso, é necessária a participação da gerência para a sua definição. Pode-se citar como exemplo alguns tipos de estratégia: aumentar o lucro dos produtos, reforçar imagem do produto nas diferentes áreas (preço, variedade, etc.), aumentar a participação de mercado dos produtos, entre outras.

$\mathrm{Na}$ etapa 6 são decididas as ações que devem ser tomadas para alcançar as estratégias definidas. Assim como para as estratégias, a definição das táticas também deve visar atingir as metas das categorias. Esta etapa também necessita do envolvimento dos gestores para aprovação. Podem-se citar alguns exemplos de táticas de categorias: exposição diferenciada, promoções, negociações com os fornecedores, diminuição ou aumento da margem, entre outras.

Um passo importante para a implementação do gerenciamento por categorias é a validação de todo o plano com a alta gerência da empresa. Esta aprovação é necessária para a certificação do bom andamento do gerenciamento por categorias para toda empresa. Na etapa 7, após a aprovação da diretoria, as tarefas são atribuídas aos funcionários envolvidos. Por fim, é desenvolvido um cronograma, contendo as informações de atividades, prazos e responsáveis. 
Após a execução do plano, deve ser realizada periodicamente a revisão das categorias (etapa 8), bem como o acompanhamento do desempenho de cada uma, a fim de verificar se as metas estão sendo cumpridas. Sugere-se pelo menos uma revisão anual. O mix de produtos trabalhados deve ser revisado, a fim de excluir aqueles que não apresentem o desempenho esperado. Quando necessário o plano deve ser alterado, adequando os objetivos à situação atual da empresa.

\section{Resultados do Estudo de Caso e Discussão}

Nessa seção o gerenciamento por categorias mostrado na figura 1 é ilustrado apresentando dados da rede de farmácias.

$\mathrm{Na}$ etapa 1 foram definidas as categorias e a distribuição dos produtos dentro das mesmas. Esta etapa englobou a revisão de todos os campos do cadastro dos medicamentos, como citado na seção 3. Para os 6.000 medicamentos trabalhados foi necessário aproximadamente um mês para a revisão e alteração de cadastro. Foram definidas 24 categorias e 121 subcategorias. Por exemplo, para a categoria Dor e Febre existem as subcategorias Analgésicos, Antiespasmódicos, Tratamento da Enxaqueca, entre outras. Dependendo do desempenho de determinada categoria, surge a necessidade de análises mais pontuais. Para tanto, a análise de desempenho das subcategorias permite o melhor entendimento dos resultados, evitando a análise item a item. A Tabela 2 apresenta as categorias definidas, bem como os resultados das etapas 2 e 3 . 
Tabela 2 - Resultados das três primeiras etapas

\begin{tabular}{|c|c|c|c|c|c|c|c|c|c|}
\hline $\begin{array}{l}\text { Número da } \\
\text { categoria }\end{array}$ & Categoria & $\begin{array}{l}\text { Papel da } \\
\text { categoria }\end{array}$ & $\begin{array}{c}\text { Venda } \\
\text { quantidade }\end{array}$ & $\begin{array}{l}\text { Venda } \\
\text { Valor }\end{array}$ & Rentabilidade & $\begin{array}{l}\text { Giro de } \\
\text { estoque }\end{array}$ & $\begin{array}{r}\text { Participação } \\
\text { fornecedores }\end{array}$ & $\begin{array}{c}\text { Indicador } \\
\text { global }\end{array}$ & $\begin{array}{c}\text { Classificação } \\
\text { ABC }\end{array}$ \\
\hline 1 & Dor e Febre & Rotina & $22,1 \%$ & $10,9 \%$ & $11,9 \%$ & $10,5 \%$ & $11,1 \%$ & $13,3 \%$ & $\mathrm{~A}$ \\
\hline 2 & Alergias e Infecções & Rotina & $7,0 \%$ & $9,9 \%$ & $11,2 \%$ & $12,6 \%$ & $20,1 \%$ & $12,1 \%$ & A \\
\hline 3 & Gastrointestinais & Rotina & $17,6 \%$ & $8,6 \%$ & $10,6 \%$ & $10,2 \%$ & $11,3 \%$ & $11,6 \%$ & A \\
\hline 4 & Cardio & Rotina & $9,9 \%$ & $11,5 \%$ & $12,4 \%$ & $11,5 \%$ & $12,4 \%$ & $11,5 \%$ & A \\
\hline 5 & Sistema Nervoso & Destino & $7,0 \%$ & $15,2 \%$ & $14,2 \%$ & $10,2 \%$ & $9,0 \%$ & $11,1 \%$ & A \\
\hline 6 & Pele e Mucosas & Rotina & $6,3 \%$ & $5,5 \%$ & $5,9 \%$ & $8,9 \%$ & $11,3 \%$ & $7,6 \%$ & A \\
\hline 7 & Saúde da Mulher & Rotina & $6,8 \%$ & $9,7 \%$ & $8,3 \%$ & $5,5 \%$ & $2,1 \%$ & $6,5 \%$ & A \\
\hline 8 & Gripes e Resfriados & Rotina & $8,9 \%$ & $3,8 \%$ & $4,5 \%$ & $5,8 \%$ & $7,8 \%$ & $6,2 \%$ & A \\
\hline 9 & Vida Saudável & Conveniência & $2,3 \%$ & $3,5 \%$ & $2,8 \%$ & $5,1 \%$ & $2,3 \%$ & $3,2 \%$ & B \\
\hline 10 & Colesterol e Triglicerídeos & Rotina & $2,0 \%$ & $5,2 \%$ & $4,1 \%$ & $2,5 \%$ & $1,9 \%$ & $3,2 \%$ & B \\
\hline 11 & Olhos e Ouvidos & Rotina & $2,3 \%$ & $3,5 \%$ & $2,8 \%$ & $3,7 \%$ & $2,5 \%$ & $3,0 \%$ & B \\
\hline 12 & Diabetes & Destino & $2,0 \%$ & $3,2 \%$ & $2,7 \%$ & $3,4 \%$ & $2,5 \%$ & $2,8 \%$ & $\mathrm{C}$ \\
\hline 13 & Saúde do Homem & Rotina & $1,0 \%$ & $3,1 \%$ & $3,1 \%$ & $1,6 \%$ & $1,6 \%$ & $2,1 \%$ & $\mathrm{C}$ \\
\hline 14 & Circulatórios & Rotina & $0,9 \%$ & $1,7 \%$ & $1,5 \%$ & $2,2 \%$ & $1,3 \%$ & $1,5 \%$ & $\mathrm{C}$ \\
\hline 15 & Dor e Contusão & Rotina & $1,4 \%$ & $0,9 \%$ & $0,9 \%$ & $1,1 \%$ & $1,4 \%$ & $1,1 \%$ & $\mathrm{C}$ \\
\hline 16 & Sistema Endócrino & Conveniência & $1,2 \%$ & $1,2 \%$ & $1,0 \%$ & $1,6 \%$ & $0,4 \%$ & $1,1 \%$ & $\mathrm{C}$ \\
\hline 17 & Emagrecedores & Ocasional & $0,3 \%$ & $0,8 \%$ & $0,8 \%$ & $0,6 \%$ & $0,4 \%$ & $0,6 \%$ & $\mathrm{C}$ \\
\hline 18 & Sistema Sanguíneo & Rotina & $0,4 \%$ & $0,6 \%$ & $0,5 \%$ & $1,0 \%$ & $0,2 \%$ & $0,5 \%$ & $\mathrm{C}$ \\
\hline 19 & Oncológicos & Rotina & $0,1 \%$ & $0,5 \%$ & $0,3 \%$ & $1,1 \%$ & $0,1 \%$ & $0,4 \%$ & $\mathrm{C}$ \\
\hline 20 & Calmantes Naturais & Conveniência & $0,3 \%$ & $0,3 \%$ & $0,3 \%$ & $0,4 \%$ & $0,1 \%$ & $0,3 \%$ & $\mathrm{C}$ \\
\hline 21 & Transplantes & Ocasional & $0,0 \%$ & $0,1 \%$ & $0,1 \%$ & $0,2 \%$ & $0,0 \%$ & $0,1 \%$ & $\mathrm{C}$ \\
\hline 22 & Estimulantes Apetite & Rotina & $0,1 \%$ & $0,0 \%$ & $0,0 \%$ & $0,2 \%$ & $0,1 \%$ & $0,1 \%$ & $\mathrm{C}$ \\
\hline 23 & Vacinas & Ocasional & $0,0 \%$ & $0,1 \%$ & $0,0 \%$ & $0,1 \%$ & $0,0 \%$ & $0,0 \%$ & $\mathrm{C}$ \\
\hline 24 & Antídotos & Ocasional & $0,0 \%$ & $0,0 \%$ & $0,0 \%$ & $0,0 \%$ & $0,0 \%$ & $0,0 \%$ & $\mathrm{C}$ \\
\hline
\end{tabular}

A partir da análise do resultado de venda e rentabilidade, as categorias foram distribuídas entre os quatro papéis sugeridos na literatura: categorias de destino, de rotina (ou preferido), ocasional (ou sazonal) e de conveniência. A validação dos papéis das categorias foi realizada em uma reunião com a equipe de gerenciamento por categorias, os gestores da área, a farmacêutica da empresa e o setor de marketing. Das 24 categorias analisadas duas se enquadram na definição de categorias de destino, que são aquelas que ajudam a definir o papel do varejista e em que ele é o principal provedor; quinze foram definidas como categorias de rotina, onde as categorias auxiliam a construir a imagem do varejista perante o consumidor; quatro têm características de categorias ocasionais, que são aquelas em que o varejista é um provedor importante, mas são categorias secundárias na geração de resultados; e três foram definidas como categorias de conveniência, que são aquelas que objetivam que o consumidor encontre tudo o que precisa em um único local.

Para a etapa de avaliação das categorias, foram selecionados indicadores para a avaliação de desempenho. A seleção ocorreu em reuniões internas, onde estavam presentes a coordenadora e o gerente da equipe de gerenciamento por categorias. Os indicadores selecionados foram cinco: quantidade de venda, valor de venda efetiva (valor efetivamente pago pelo consumidor), rentabilidade, giro de estoque e participação dos fornecedores (para dimensionar se o fornecedor de cada item é parceiro da empresa).

Os indicadores foram calculados a partir das fórmulas das equações (1), (2), (3) e (4). $\mathrm{O}$ indicador de participação dos fornecedores foi selecionado para a avaliação por se enquadrar nos objetivos específicos da empresa em questão. Este indicador é calculado por meio da divisão do valor investido pelo fornecedor pelo total de venda em valor de cada item, ou seja, representa o percentual de investimento em relação à venda.

Os dados utilizados para a medição foram coletados em um período de seis meses. O indicador global de cada item foi calculado por meio da média dos cinco indicadores 
selecionados. A classificação dos produtos dentro das categorias é interessante para a priorização de medicamentos a serem envolvidos em ações, como por exemplo, as exposições citadas na seção 3. Além disso, a soma dos resultados de cada item possibilita a obtenção de um resultado único para a categoria a que pertencem, permitindo classificar e priorizar as diferentes categorias. O resultado obtido reflete os atuais interesses da empresa, pois as ações já desenvolvidas envolvem as categorias de classe A e B, que são aquelas que apresentam melhor desempenho.

A fim de viabilizar a execução de todos os procedimentos propostos, as etapas quatro, cinco e seis serão exemplificadas apenas para as categorias de classe A e B, que podem ser visualizadas na Tabela 2.

O desenvolvimento do cartão de metas das categorias foi realizado a partir de análise do histórico de vendas dos últimos 3 anos (2008 a 2010) e de fatores externos que podem influenciar a demanda, como por exemplo, a previsão de um inverno mais rigoroso ou uma nova legislação em relação à dispensação dos medicamentos. A definição das metas foi construída em reuniões com a equipe de gerenciamento de categorias, a coordenadora e o gerente da área, com base nas informações já levantadas. A Tabela 3 apresenta as metas de evolução para cada indicador para o ano de 2011. As metas definidas são em percentual em relação aos resultados absolutos dos indicadores.

Tabela 3 - Metas de evolução para cada indicador

\begin{tabular}{cccccccc}
\hline $\begin{array}{c}\text { Número da } \\
\text { categoria }\end{array}$ & Categoria & $\begin{array}{c}\text { Classificação } \\
\text { ABC }\end{array}$ & $\begin{array}{c}\text { Meta } \\
\text { quantidade }\end{array}$ & $\begin{array}{c}\text { Meta } \\
\text { valor }\end{array}$ & $\begin{array}{c}\text { Meta } \\
\text { rentabilidade }\end{array}$ & $\begin{array}{c}\text { Meta } \\
\text { giro }\end{array}$ & $\begin{array}{c}\text { Meta participação } \\
\text { fornece dores }\end{array}$ \\
\hline 1 & Dor e Febre & $\mathrm{A}$ & $4,1 \%$ & $16,1 \%$ & $20,5 \%$ & $8,0 \%$ & $4,0 \%$ \\
2 & Alergias e Infecções & $\mathrm{A}$ & $3,4 \%$ & $4,7 \%$ & $10,2 \%$ & $6,0 \%$ & $3,0 \%$ \\
3 & Gastrointestinais & $\mathrm{A}$ & $9,4 \%$ & $13,4 \%$ & $23,2 \%$ & $5,0 \%$ & $4,0 \%$ \\
4 & Cardio & $\mathrm{A}$ & $21,9 \%$ & $10,9 \%$ & $28,8 \%$ & $6,0 \%$ & $4,0 \%$ \\
5 & Sistema Nervoso & $\mathrm{A}$ & $14,3 \%$ & $13,1 \%$ & $30,7 \%$ & $7,0 \%$ & $2,0 \%$ \\
6 & Pele e Mucosas & $\mathrm{A}$ & $10,6 \%$ & $11,5 \%$ & $14,2 \%$ & $6,0 \%$ & $2,0 \%$ \\
7 & Saúde da Mulher & $\mathrm{A}$ & $8,2 \%$ & $10,8 \%$ & $15,2 \%$ & $4,0 \%$ & $5,0 \%$ \\
8 & Gripes e Resfriados & $\mathrm{A}$ & $7,9 \%$ & $13,2 \%$ & $12,5 \%$ & $8,0 \%$ & $5,0 \%$ \\
9 & Vida Saudável & $\mathrm{B}$ & $20,0 \%$ & $25,7 \%$ & $24,1 \%$ & $7,0 \%$ & $3,0 \%$ \\
10 & Colesterol e Triglicerídeos & $\mathrm{B}$ & $32,5 \%$ & $12,1 \%$ & $14,7 \%$ & $7,0 \%$ & $2,0 \%$ \\
11 & Olhos e Ouvidos & $\mathrm{B}$ & $11,7 \%$ & $16,9 \%$ & $25,1 \%$ & $5,0 \%$ & $2,0 \%$ \\
\hline
\end{tabular}

$\mathrm{Na}$ etapa 5 sugere-se analisar pontualmente o mercado e os principais consumidores de cada categorias para escolher a estratégia adequada. As categorias 1, 3, 6 e 8 são compostas principalmente de MIPs (medicamentos isentos de prescrição) e são categorias de papel de rotina, por isso a estratégia selecionada é de reforçar a imagem das principais marcas. Como existem muitos medicamentos para combater os mesmos sintomas, o que faz com que o consumidor decida pela compra é a preferência por alguma marca específica ou a visibilidade dos produtos. A categoria 9 tem papel de conveniência e é composta principalmente por produtos registrados como alimentos, que são em sua maioria vitaminas. Logo, a estratégia indicada também é a de reforçar a imagem das marcas mais vendidas.

A categoria 2 tem papel de rotina e é representativa em valor para a empresa, mas sofre com a redução de demanda a partir da definição da RDC 44 (ANVISA, 2010), que determina a proibição da dispensação de antibióticos sem a retenção de receita. Para esta categoria a estratégia ideal é desenvolver o aumento da prescrição médica direcionada à rede estudada. As categorias 4, 7 e 10 têm papel de rotina e são compostas em sua maioria por medicamentos de uso contínuo, como por exemplo, anti-hipertensivos, anticoncepcionais e 
medicamentos que auxiliam a redução do colesterol, respectivamente. Por este motivo, a estratégia indicada é a de promover os medicamentos através de promoções que induzam os clientes a criarem fidelidade à rede. A categoria 5 tem papel de destino e é caracterizada pelo alto valor de seus produtos, tendo em sua maioria clientes que buscam o bom atendimento. Logo, a estratégia indicada para esta categoria é a diferenciação no atendimento. A categoria número 11 é composta tanto por MIPs quanto por medicamentos tarjados, portanto, para esta categoria, a estratégia deve ser diferente para os diferentes tipos de produtos. A Tabela 4 apresenta as estratégias selecionadas para estas categorias, assim como as táticas indicadas na etapa seis.

As táticas adotadas na etapa 6 servem de base para a execução das estratégias definidas na etapa anterior. Partindo deste princípio, para as categorias 1, 3, 6, 8 e 9 a tática indicada é desenvolver exposições diferenciadas para as principais marcas que pertencem a elas. Os medicamentos das categorias 1 e 8, em sua maioria, não podem ser expostos ao alcance do consumidor. Logo, podem compor uma exposição atrás do balcão de atendimento, onde ficam visíveis ao consumidor, mas não estão ao seu alcance. Já as categorias 3, 6 e 9 são compostas por medicamentos fitoterápicos, tópicos e com registro de alimento, respectivamente, logo, podem estar ao alcance do consumidor. Desta maneira é indicada a exposição destes grupos no autosserviço. A tática das categorias 7 e 10 é desenvolver promoções diferenciadas a partir de negociação com os fornecedores, pois estes consumidores compram frequentemente os mesmos medicamentos.

Como os principais medicamentos da categoria 4 fazem parte de um programa brasileiro que possibilita que o consumidor adquira certos medicamentos gratuitamente ou com até $90 \%$ de desconto, a tática selecionada é a divulgação massiva de que a rede participa do programa. Para que se aumente o número de prescrições indicadas à rede, a tática indicada para a categoria 2 é investir na visitação médica, divulgando os descontos da rede. Para atingir o bem estar desejado pelos consumidores da categoria 5, a tática sugerida é investir em treinamento da equipe de ponto-de-venda, com o objetivo de obter diferenciação no atendimento. Como a categoria 11 possui produtos que podem ser expostos no autosserviço, como os produtos para lentes de contato, colírios para glaucoma e outras doenças oculares, sugere-se que sejam exploradas promoções para o consumidor.

Tabela 4 - Estratégias e Táticas adotadas para as principais categorias

\begin{tabular}{cccc}
\hline $\begin{array}{c}\text { Número da } \\
\text { categoria }\end{array}$ & Categoria & Estratégia & Tática \\
\hline 1 & Dor e Febre & Reforçar a imagem das principais marcas & Exposição diferenciada atrás do balcão \\
2 & Alergias e Infeç̧ões & Aumentar a prescrição médica & Visitação médica \\
3 & Gastrointestinais & Reforçar a imagem das principais marcas & Exposição diferenciada no autosserviço \\
4 & Cardio & Reforçar a imagem de preço mais acessível & Divulgação da Farmácia Popular \\
5 & Sistema Nervoso & Reforçar a sensação de diferenciação no atendimento & Treinamento aos balconistas \\
6 & Pele e Mucosas & Reforçar a imagem das principais marcas & Exposição diferenciada no autosserviço \\
7 & Saúde da Mulher & Reforçar a imagem de preço mais acessível & Ações específicas com promoções \\
8 & Gripes e Resfriados & Reforçar a imagem das principais marcas & Exposição diferenciada atrás do balcão \\
9 & Vida Saudável & Reforçar a imagem das principais marcas & Exposição diferenciada no autosserviço \\
10 & Colesterol e Triglicerídeos & Reforçar a imagem de preço mais acessível & Ações específicas com promoções \\
11 & Olhos e Ouvidos & Reforçar imagem das marcas/preço acessível & Exposição no autosserviço/ promoções \\
\hline
\end{tabular}

Para as definições relacionadas à estratégia das categorias é útil o conhecimento avançado sobre os produtos trabalhados e suas especificações. Apenas com experiência no assunto pode-se compreender o mercado e então definir as diretrizes a serem tomadas para cada tipo de produto. Como indicado na etapa 7, a proposta de implementação foi apresentada e validada com a diretoria da empresa. Na primeira revisão das categorias (etapa 8), não houve modificação na composição das mesmas. 


\section{Conclusões}

Levando-se em consideração o constante crescimento do mercado, as necessidades de adaptação às exigências da legislação e a mudança de fatores ambientais, surge a necessidade de desenvolver estratégias diferenciadas para os diferentes produtos. O presente trabalho apresentou a estrutura da implementação do gerenciamento por categorias para medicamentos em uma rede de farmácias, a fim de direcionar as ações realizadas para as diferentes categorias de produtos. Com base na literatura sobre gerenciamento por categorias, definiu-se a utilização do procedimento metodológico adotado por Merlo et al. (2004).

Sob o aspecto acadêmico, os resultados permitiram classificar as diferentes categorias a partir de um indicador global, possibilitando a seleção de categorias e produtos para o desenvolvimento de ações diferenciadas para cada categoria. Também confirmaram a percepção de que com o adequado desenvolvimento das categorias e atribuição dos produtos a elas, o desempenho geral da categoria será aumentado. Esta percepção confirma o princípio de gerenciar as categorias como se fossem diferentes unidades de negócios de uma empresa. A execução periódica da revisão das categorias é importante para evitar que produtos com desempenho ruim prejudiquem o desempenho de toda a categoria.

A partir da avaliação de desempenho das categorias por indicadores que refletem os objetivos da empresa, é possível focar o trabalho nas principais categorias trazendo melhores resultados para a empresa. Através do acompanhamento do desempenho ao longo do tempo, podem-se verificar as quedas de desempenho e desenvolver ações para recuperar o desempenho.

Como trabalho futuro, sugere-se aperfeiçoar e melhorar os indicadores utilizados na formação das categorias e testar indicadores globais com diferentes ponderações dos indicadores parciais.

\section{Referências}

Agência Nacional de Vigilância Sanitária, 2009b. INSTRUÇÃO NORMATIVA Nº10 - IN $\mathrm{N}^{\circ} 10$, de 17 de agosto de 2009. Disponível em:

$<$ http://www.cff.org.br/userfiles/file/noticias/in10_170809.pdf>. Acesso em: 08 mar. 2012.

Agência Nacional de Vigilância Sanitária, 2009a. RESOLUÇÃO DA DIRETORIA COLEGIADA - RDC No 44, de 17 de agosto de 2009. Disponível em: < http://cfo.org.br/wpcontent/uploads/ 2010/02/180809_rdc_44.pdf>. Acesso em: 08 mar. 2012.

Agência Nacional de Vigilância Sanitária, 2010. RESOLUÇÃO DA DIRETORIA

COLEGIADA - RDC No 44, de 26 de outubro de 2010. Disponível em:

http://bvsms.saude.gov.br/bvs/saudelegis/anvisa/2010/res0044_26_10_2010.html >.Acesso em: 08 mar. 2012.

ALBUQUERQUE, A. F.; ESCRIVÃO F., E. Gestão estratégica das informações na pequena empresa hoteleira: apresentação de propostas de melhoria no gerenciamento das informações internas. Revista de Gestão USP, São Paulo, v. 14, n. 4, p.47-62, out.-dez. 2007.

BARRATT, M.; OLIVEIRA, A. Exploring the experiences of collaborative planning initiatives. International Journal of Physical Distribution \& Logistics Management, Cranfield, v. 31, n.4, p.266-289, 2001.

BLESSA, R. Merchandising no Ponto de Venda. 2ed. São Paulo: Atlas, 2003.

BORTOLUZZI, S.; ENSSLIN, S.; ENSSLIN L.; RODRIGUES, E. Práticas de avaliação de desempenho organizacional em pequenas e médias empresas: Investigação em uma empresa de porte médio do ramo moveleiro. Revista Produção Online, v.10, n.3, p.551-576, set. 2010. 
CAMARGOS, M. A.; BARBOSA, F. V. Da fusão Antártica/Brahma à fusão com a Interbrew: uma análise da trajetória econômico-financeira e estratégica da Ambev. Revista de Gestão USP, São Paulo, v. 12, n. 3, p.47-63, jul.-set. 2005.

CHIUSOLI, C. L.; PACAGNAN, M. A importância das informações de mercado como apoio à tomada de decisões de marketing. Revista de Gestão USP, São Paulo, v. 16, n. 2, p.83-100, abr.-jun. 2009.

COSTA, J. S., BRAZIL, C. A., OLIVEIRA, M. B. Metodologia multicritério e ECR: utilização no mercado varejista. Revista Produção, v.13, n.2, p.114-122, 2003.

ECR Brasil, 2001. Gerenciamento por Categoria. Disponível em: < http://www.ecrbrasil.com.br/ecrbrasil/page/gerenciamentocategoria.asp $>$. Acesso em: 08 mar. 2012.

ECR Brasil. Gerenciamento por Categorias: Melhores Práticas. São Paulo: Associação ECR Brasil, 1998b.

ECR Brasil. Visão Geral: Potencial de Redução de Custos e Otimização de Processos. São Paulo: Associação ECR Brasil, 1998a.

FERREIRA, M. Melhoria do processo decisório estratégico de uma corretora de seguros através da metodologia BSC. Trabalho de conclusão (Especialização em Administração) Escola de Administração, Universidade Federal do Rio Grande do Sul, Porto Alegre, 2009. $45 \mathrm{p}$.

GUEDES, T. A. Procedimentos de otimização no planejamento e controle da qualidade de produtos e processos. Trabalho de conclusão (Especialização em Engenharia de Produção) Escola de Engenharia, Universidade Federal de Santa Catarina, Florianópolis, 1996.

HAUCK, E. Um estudo sobre a implantação da ferramenta gerenciamento por categorias no varejo de farmácias. 2008. 70p. Trabalho de conclusão (Graduação em Administração) Escola de Administração, Universidade Federal do Rio Grande do Sul, Porto Alegre, 2008.

IMS Health, 2011. The Global Use of Medicines: Outlook through 2015. Disponível em: $<$ http://www.imshealth.com/deployedfiles/imshealth/Global/Content/IMS\%20Institute/Static \%20File/Global_Use_of_Medicines_Report.pdf $>$. Acesso em: 08 mar. 2012.

Instituto Brasileiro de Geografia e Estatística (IBGE), 2011. Vendas no varejo variam 0,3\% em dezembro e fecham 2011 em 6,7\%. Disponível em:

http://www.ibge.gov.br/home/presidencia/noticias/noticia_visualiza.php?id_noticia=2086\&id pagina $=1>$. Acesso em: 08 mar. 2012.

KLOTZLE, M. C; O impacto da formação de alianças estratégicas no valor de mercado e no desempenho econômico-financeiro das empresas. Caderno de Pesquisas em Administração, São Paulo, v.10, n.4, p.33-46, out.-dez. 2003.

MARQUES, E. F.; ALCÂNTARA, R. L. C. O uso da ferramenta gerenciamento por categoria na gestão da cadeia de suprimentos: um estudo multicaso. Revista Gestão \& Produção, São Carlos, v.11, n.2, p.153-164, mai.-ago. 2004.

MELO, P. H. A.; LIMA, I. B. Estudo sobre o posicionamento físico de analgésicos e antitérmicos nas farmácias líderes e sua relação com o comportamento do consumidor.

ENCONTRO NACIONAL DE ENGENHARIA DE PRODUÇÃO, XXIX, 2009, Salvador.

MERLO, E.; MAUAD, T.; NAGANO, M. Um modelo simplificado da prática de gerenciamento por categorias no varejo de médio porte. Revista de Administração, São Paulo, v.39, n.1, p.30-41, jan.-mar. 2004. 
MORESI, E. Metodologia de Pesquisa. 2003. 108p. Trabalho de Conclusão (Especialização em Gestão do Conhecimento e Tecnologia da Informação) - Universidade Católica de Brasília, 2003.

MULLER, Cláudio. Modelo de gestão integrando planejamento estratégico, sistemas de avaliação de desempenho e gerenciamento de processos (MEIO - modelo de estratégia indicadores e operação). Tese (Doutorado em Engenharia de Produção) - Escola de Engenharia, Universidade Federal do Rio Grande do Sul, Porto Alegre, 2002. 292p.

PINHEIRO, A. C. M. Gerenciamento de estoque farmacêutico. Revista Eletrônica de Contabilidade. v.1., n.3, mar.-mai. 2005.

PIRES, S. R. I. Gestão da cadeia de suprimentos: conceitos, estratégias, práticas e casos. 1ed. São Paulo: Atlas, 2004.

RAMUSKI, C. L. ECR e o consumidor: um estudo sobre o comportamento do consumidor em relação aos valores ofertados pelo ECR. Tese (Doutorado em Administração) - Escola de Administração de Empresas, Fundação Getúlio Vargas, São Paulo, 2004.

SLACK, N.; CHAMBERS, S.; JOHNSTON. R. Administração da Produção. 2ed. São Paulo: Atlas, 2007. 